\title{
A apropriação de conceitos científicos no contexto escolar e as pedagogias do aprender a aprender
}

\author{
Patricia Verlingue Ramires Monteiro \\ Universidade Federal do Paraná - Curitiba - PR - Brasil \\ Graziela Lucchesi Rosa da Silva \\ Universidade Federal do Paraná - Curitiba - PR - Brasil \\ João Henrique Rossler \\ Universidade Federal do Paraná - Curitiba - PR - Brasil
}

\begin{abstract}
Resumo
O artigo objetiva discutir teoricamente como a escola atua na apropriação de conceitos científicos e como essa atuação pode se alienar. Justifica-se este estudo por trazer acréscimos à Psicologia e à Educação, evidenciando o pensamento por conceitos como elemento cognitivo essencial do processo de elaboração do conhecimento. A partir da Psicologia Histórico-Cultural evidencia-se o papel da escola na mediação do desenvolvimento dos conceitos espontâneos e científicos no sistema interfuncional da consciência. Além disso, como este papel mediador e este desenvolvimento podem se alienar por conta das tendências pedagógicas atuais, como as Pedagogias do Aprender a Aprender, consideradas a expressão ideológica da materialidade da sociedade de classes contemporânea. Por último, defende que a escola deve se ater ao conhecimento sistematizado e não ao conhecimento espontâneo; ao conhecimento fruto da prática e da teorização histórico-social humana e não ao conhecimento pragmático e construído individualmente; ao saber totalizante e não ao saber fragmentado.
\end{abstract}

Palavras-chave: Conceitos; educação; Psicologia Histórico-Cultural.

\section{The appropriation of scientific concepts in school context and the pedagogies of learning to learn}

\begin{abstract}
The article aims to discuss theoretically how the school acts in the appropriation of scientific concepts and how this action can be alienated. This study is justified because it brings contribution to Psychology and Education, evidencing thinking by concepts as an essential cognitive element of the process of knowledge elaboration. From Historical-Cultural Psychology the role of the school in the mediation of the development of spontaneous and scientific concepts in the inter-functional system of consciousness is evidenced. Moreover, how this mediating role and this development can be alienated by present pedagogical tendencies, such as the Learning to Learn Pedagogies, considered the ideological expression of the materiality of the contemporary class society. Finally, he argues that the school should stick to systematized knowledge and not to spontaneous knowledge; to the knowledge derived from human historical and social theorization and practice, and not from individual pragmatic knowledge; to totalizing knowledge and not to fragmented knowledge.
\end{abstract}

Keywords: Concepts; education; Historical Cultural Psychology

\section{La apropiación de conceptos científicos en el contexto escolar y las pedagogías del aprender a aprender}

\section{Resumen}

El presente artículo tiene por objetivo discutir teóricamente cómo la escuela actúa en la apropiación de conceptos científicos y cómo esa actuación pude alienarse. Se justifica este estudio por traer adicción a la Psicología y a la Educación, evidenciando el pensamiento por conceptos como elemento cognitivo esencial del proceso de elaboración del conocimiento. A partir de la Psicología Histórico-Cultural se evidencia el papel de la escuela en la mediación del desarrollo de los conceptos espontáneos y científicos en el sistema inter-funcional de la consciencia. Además de eso, como este papel mediador y este desarrollo pueden alienarse por cuenta de las tendencias pedagógicas actuales, como las Pedagogías del Aprender a Aprender, consideradas la expresión ideológica de la materialidad de la sociedad de clases contemporánea. Por último, defiende que la escuela debe atenerse al conocimiento sistematizado y no al conocimiento espontáneo; al conocimiento fruto de la práctica y de la teorización histórico-social humana y no al conocimiento pragmático y construido individualmente; al saber totalizante y no al saber fragmentado.

Palabras clave: Conceptos; educación; Psicología Histórico-Cultural. 


\section{Introdução}

Vygotsky (1998) é enfático ao afirmar que a apropriação dos conceitos científicos é essencial para o desenvolvimento das funções psicológicas superiores. O desenvolvimento das funções psicológicas superiores, tipicamente humanas, demanda a superação das funções elementares - como a memória natural, a atenção involuntária, a inteligência prática etc. - em direção à conquista de novas propriedades, de propriedades superiores - o pensamento abstrato, a atenção voluntária, a memória lógica, dentre outras. Tal superação não ocorre de maneira natural e espontânea, mas como fruto das apropriações do patrimônio material e intelectual pelo individuo singular, o que depende, por sua vez, de suas condições objetivas de vida e aprendizagens (Abrantes \& Martins, 2006).

Sob os fundamentos da Psicologia Histórico-Cultural, entende-se que o processo de apropriação-objetivação ${ }^{1}$ desses conceitos demanda situações pedagógicas específicas, disponibilizadas majoritariamente no contexto da escola, pois seu desenvolvimento requer que essas situações sejam sistematizadas e intencionalmente organizadas (Klein, 2007), o que comumente não ocorre no contexto extraescolar. Isso porque a escola conta (ou ao menos deveria contar) com determinadas condições (estrutura, vivências, conteúdos, recursos materiais e pessoais) favoráveis à produção de processos de ensino-aprendizagem de caráter não espontâneo, os quais atuam sobre o desenvolvimento psíquico dos sujeitos de modo qualitativamente distinto dos processos que ocorrem na vida em geral.

Dessa forma, o processo de apropriação-objetivação do saber sistematizado, desenvolvido ao longo da história e acumulado objetivamente na forma do conhecimento filosófico e científico, expresso em conceitos, ocorre na sociedade hoje essencialmente a partir do seu ensino organizado e planejado no contexto escolar. Neste processo, ocorre o

1 Duarte (2005) explica que objetivação se constitui na atividade física e/ou mental dos seres humanos, cujas características e propriedades se transferem para os seus produtos, isto é, se corporificam nesse produto, o qual passa a ter, portanto, uma função específica na prática social, tornando-se objeto de uma dada apropriação. O conceito de objetivação, portanto, refere-se tanto à atividade humana (atividade objetivadora) quanto ao seu produto. Já a apropriação é processo ativo pelo qual o indivíduo assimila as objetivações materiais e simbólicas de uma determinada cultura, resultantes da atividade objetivadora das gerações passadas, as quais contêm a experiência sócio-histórica da humanidade acumulada objetivamente, isto é, como objeto de apropriação. $\mathrm{E}$ como se realiza este processo? De acordo com Leontiev, "para se apropriar dos objectos ou dos fenómenos que são o produto do desenvolvimento histórico, é necessário desenvolver em relação a eles uma actividade que reproduza, pela sua forma, os traços essenciais da atividade encarnada, acumulada no objeto" (Leontiev, 1978. p. 268). Portanto, a dinâmica entre apropriação e objetivação "é o processo mediador entre o processo histórico de formação do gênero humano e o processo de formação de cada indivíduo como um ser humano" (Duarte, 2005. p. 33), de modo que a transmissão das criações do gênero humano às gerações mais recentes acontece mediante um processo educativo, no sentido lato do termo, em que as novas gerações se apropriam dos elementos culturais materiais e simbólicos historicamente produzidos até o momento. desenvolvimento do pensamento teórico, forma mais complexa de pensamento e que opera por meio de conceitos, o qual transforma qualitativamente a própria consciência do estudante (Abrantes \& Martins, 2006). Note-se que não se trata de afirmar que esse processo ocorra somente na escola, mas sim que, pelo processo de escolarização, há uma potencialização desse desenvolvimento.

No entanto, consideramos que, sob a influência do conjunto das ideias filosóficas, psicológicas e pedagógicas atuais, afinado com o projeto capitalista neoliberal de sociedade e denominado por Duarte $(2004,2008)$ como "ideário do aprender a aprender", esses processos escolares e, por conseguinte, a apropriação de conceitos científicos podem se alienar, como procuraremos demonstrar ao longo do artigo.

Ante o exposto, buscaremos por meio de revisão teórico-conceitual baseada em autores clássicos da Psicologia Histórico-Cultural e em autores contemporâneos, discorrer, num primeiro momento, sobre o papel da linguagem e dos signos no desenvolvimento histórico e ontogenético humano, com a finalidade de fornecer as bases para a compreensão do papel da escola na apropriação de conceitos científicos. Em seguida, analisaremos como as tendências pedagógicas do Aprender a Aprender contribuem para o esvaziamento e empobrecimento da função da escola no desenvolvimento psicológico dos estudantes, à medida que secundarizam a transmissão do conhecimento e o papel do professor no ensino, valorizando as aprendizagens espontâneas, não sistemáticas, do estudante. O que pode limitar a apropriação dos fundamentos explicativos do conhecimento - dos conceitos científicos - posto que, pela sua complexidade, a apropriação desses conceitos não pode ocorrer de modo livre e espontâneo, isto é, a partir da construção autônoma do aluno.

\section{A apropriação de conceitos científicos na escola sob os fundamentos da Psicologia Histórico- Cultural}

De acordo com Luria (1979), a palavra e o conceito são expressões das atividades intelectuais humanas mais complexas, porque condensam a experiência e o conhecimento humano historicamente produzido. Ao se apropriar dos códigos da língua, o sujeito passa a dispor de condições que o direcionam a ultrapassar os limites da percepção sensorial imediata do mundo externo. Para Luria (1979), o ser humano em desenvolvimento não dispõe apenas do pensamento prático direto, mas se torna capaz, dada a apropriação de objetivações humanas, de refletir conexões e relações complexas, de formar conceitos, de inferir conclusões, podendo solucionar questões teóricas. Dessa forma, a apropriação de signos socialmente produzidos, ao longo da história da humanidade, leva ao desenvolvimento de complexas atividades afetivo-cognitivas. Sobre a apropriação de signos, Martins (2011) explica que

O signo, então, opera como um estímulo de segunda ordem que, retroagindo sobre as funções psíquicas, transforma 
suas expressões espontâneas em expressões volitivas. As operações que atendem aos estímulos de segunda ordem conferem novos atributos às funções psíquicas, e por meio deles o psiquismo humano adquire um funcionamento qualitativamente superior e liberto tanto dos determinismos biológicos quanto do contexto imediato de ação (Martins, 2011, p. 40, grifo da autora).

$\mathrm{Na}$ atividade humana, portanto, se desenvolvem uma série de dispositivos artificiais, os quais auxiliam o homem no domínio de seus próprios processos psíquicos. Esses dispositivos são essenciais à composição psíquica humana, assim como os instrumentos, frutos da atividade vital humana - o trabalho -, o são à constituição do próprio homem. Por isso, Vygotsky (1997) os denomina de signos ou instrumentos psicológicos. Como exemplo, pode-se citar a linguagem, a numeração, o cálculo, os dispositivos mnemotécnicos, a arte, a escrita etc. Os instrumentos psicológicos são criações sociais artificiais que se destinam ao autodomínio dos processos psicológicos; são concretos como os instrumentos de trabalho, pois potencializam e facilitam a atividade produtiva, servindo de mediadores entre a consciência humana e o mundo externo.

Vale destacar, conforme aponta Luria (1991), que a linguagem é o meio mais importante de desenvolvimento da consciência, posto que é "um sistema de códigos por meio dos quais são designados os objetos do mundo exterior, suas ações, qualidades, relações entre eles, etc." (Luria, 1991, p. 78., grifos do autor). Desta forma, o pensamento por conceitos está intimamente conectado à construção da linguagem, em que a palavra é a unidade fundamental. Segundo Luria (1979), a estrutura da palavra permite a formação de conceitos e a conexão entre palavras na forma de um sistema sintático e semântico complexo que gera a possibilidade de se executar operações lógicas também complexas. A palavra apresenta, prioritariamente, duas funções básicas, as quais Luria (1979) denomina como: representação material (ou seja, a função representativa da palavra que designa objetos) e significado (isto é, a função básica de representar um determinado objeto). De acordo com Luria (1979), o significado da palavra permite uma análise das práticas relacionadas aos objetos dispostos socialmente, além de permitir também uma distinção estrutural entre esses objetos, em que suas propriedades podem ser relacionadas a determinadas categorias abstratas e generalizadas. Nesse sentido, se entende a palavra como meio de abstração e generalização, sendo que a conexão entre palavras, constituindo frases, desenrola um universo de significações que reestruturam as funções psíquicas.

Deste modo, a formação dos conceitos está atrelada ao papel fundamental da palavra na complexificação do psiquismo humano. Ao se formular e se apropriar de conceitos socialmente produzidos, o ser humano tem sua estrutura psíquica potencializada, pois para operar por meio de conceitos o sujeito necessita de mudanças substancias nos seus processos psíquicos (atenção, memória, linguagem, imagina- ção, pensamento, entre outros), o que demanda, por sua vez, mobilizar todo o sistema interfuncional de seu psiquismo.

Vygotsky (1998), assim como Luria (1979), distingue a categoria conceitos em duas formas fundamentais, os conceitos espontâneos e os conceitos científicos (ou não-espontâneos), e identifica três estágios básicos à formação de conceitos no decorrer do desenvolvimento do pensamento abstrato: os agrupamentos sincréticos, a formação de complexos e os conceitos propriamente ditos. Esses estágios vão se complexificando e se desenvolvendo pelo processo de apropriação do conhecimento humano histórica e socialmente elaborado, o qual encarna a dinâmica entre conceitos espontâneos e científicos. Para Luria (1979),

É natural que sejam totalmente distintos a estrutura dos dois tipos de conceito e o sistema dos processos psicológicos que participam da formação deles: nos conceitos "comuns" [espontâneos] predominam as relações circunstanciais concretas, nos "científicos", as relações lógicas abstratas. Os conceitos "comuns" se formam com a participação da atividade prática e da experiência figurado-direta, os "científicos", com a participação determinante das operações lógico-verbais (Luria, 1979., p. 39).

Ou seja, os conceitos espontâneos, em sua maioria, são geralmente apropriados no processo de experienciação prática do mundo, isto é, partem da vivência imediata cotidiana (Vygotsky, 1998). Nesse processo, segundo Luria (1979), as relações direto-figuradas predominam, pois tais relações dizem respeito à ação imediata do sujeito, em que ele pode nomear objetos por meio de conceitos sem dispor de apropriações lógico-verbais suficientes para denominar e explicar as propriedades essenciais desses objetos. Já os conceitos não-espontâneos partem do conhecimento sistemático, científico e filosófico, produzido pelos seres humanos ao longo da história e demandam um processo de apropriação mais complexo.

Ao se apropriar de uma determinada língua, ao longo de seu desenvolvimento, a criança, por exemplo, pode se utilizar de palavras que designem conceitos científicos (por exemplo, "tempo"; "espaço"; "mamífero" etc.), sem compreender ainda, neste primeiro momento, as complexas generalizações e abrangências desses conceitos. No entanto, é somente ao longo de um processo sistemático e intencional de ensino-aprendizagem, que terá condições de compreender os fundamentos destes conteúdos, aplicando-os adequadamente em seu cotidiano. Segundo Vygotsky,

Quando uma palavra nova é aprendida pela criança, o seu desenvolvimento mal começou: a palavra é primeiramente uma generalização do tipo mais primitivo; à medida que o intelecto da criança se desenvolve, é substituída por generalizações de um tipo cada vez mais elevado - processo este que acaba por levar à formação dos verdadeiros conceitos (Vygotsky, 1998., p. 104). 
Vygotsky (1998) afirma, assim, que é na escola que a criança pode se apropriar sistematicamente das produções humanas não espontâneas, científicas, desenvolvendo qualitativamente suas funções psicológicas. Ou seja, é por meio da colaboração sistemática presente na relação professor-aluno, na sua relação mediata com o adulto, que a criança pode se apropriar dos conceitos científicos, processo este no qual ocorre o desenvolvimento mais efetivo e irreversível das suas funções psicológicas.

$\mathrm{Na}$ escola, a criança incorpora os conhecimentos de um modo distinto da experiência particular, espontânea, imediata, pragmática e concreta da vida cotidiana. E por meio da apropriação dos conceitos cientificamente sistematizados, a criança pode desenvolver teorizações, isto é, generalizações abstratas, que lhe permitem pensar sua realidade concreta de um modo qualitativamente superior. Superior no sentido de que seu pensamento, de posse destes conceitos, captura aspectos da realidade antes ocultos a sua consciência.

Esses dois tipos de conceitos - espontâneos e científicos -, portanto, não ocupam a mesma posição na vida intelectual e material do ser humano, pois refletem formas distintas de experiência e desenvolvimento psicológico. Os conceitos científicos são, de fato, o elo de conexão entre o desenvolvimento das funções psicológicas superiores e da consciência do sujeito. A esse respeito, afirma Vygotsky que,

O aprendizado escolar induz o tipo de percepção generalizante, desempenhando assim um papel decisivo na conscientização da criança dos seus próprios processos mentais. Os conceitos científicos, com seu sistema hierárquico de inter-relações, parecem constituir o meio no qual a consciência e o domínio se desenvolvem, sendo mais tarde transferidos a outros conceitos e a outras áreas do pensamento. A consciência reflexiva chega à criança através dos portais dos conhecimentos científicos (Vygotsky, 1998, p. 115).

Assim, Vygotsky (1998) remete a formação de conceitos a um sistema de relações de generalidade, isto é, em que o conceito submetido ao controle deliberado e consciente começa a fazer parte de um sistema integrado. Se a consciência pressupõe generalização, toda generalização da realidade, por sua vez, pressupõe o desenvolvimento de um conceito supra-ordenado - aquele que lança mão da existência de diversos conceitos subordinados -, o que gera uma hierarquização no sistema generalizado dos conceitos, os quais passam a apresentar diversos níveis de generalidade, numa típica combinação relacional do concreto e do abstrato (Vygotsky, 1998). Contudo, o desenvolvimento da capacidade de generalização no psiquismo da criança é potencializado por meio da relação sistemática e intencional de ensino-aprendizagem estabelecida entre professor e aluno no contexto escolar.

Facci (2004a), a partir dos escritos de Vigotski, explica esse processo. Segundo a autora, a relação entre professor e aluno não só pode produzir o desenvolvimento dos conceitos científicos, como possibilita que os conceitos espontâneos também se desenvolvam, de modo a permitir a complexificação desses conceitos em direção à condição de conceitos científicos. No contexto escolar, um conceito dito espontâneo/cotidiano como número, por exemplo, requer uma sistematização e explicação científica, de modo que o número, apenas entendido em sua praticidade cotidiana de "contar", possa adquirir novo sentido, de caráter científico no desenvolvimento intelectual do aluno. Isso ocorre, porque

[...] no campo dos conceitos científicos ocorrem níveis mais elevados de tomada de consciência do que nos conceitos espontâneos, eles se formam na escola por meio de um processo orientado, organizado e sistemático. São ensinados com a formalização de regras lógicas e a sua assimilação envolve procedimentos analíticos, iniciados por uma definição verbal, envolvendo operações mentais de abstração e generalização. Já os conceitos espontâneos, que se caracterizam pela ausência de uma percepção consciente de suas relações, são orientados pelas semelhanças concretas e por generalizações isoladas. Os conceitos espontâneos [...] se desenvolvem a partir das experiências realizadas na vida cotidiana individual, enquanto os conceitos científicos são advindos de teorias formais. No entanto, conforme Vigotski, ambos os conceitos se influem mutuamente (Facci, 2004a, pp. 223-224).

Logo, no processo de educação escolar se processa sistemática e intencionalmente a dinâmica dialética entre os conceitos espontâneos e os conceitos científicos, dando-se ênfase particular aos conceitos científicos, de modo que eles tornem mais complexas as generalizações e abstrações conceituais e viabilizem o desenvolvimento do pensamento teórico, o qual amplia o domínio das situações cotidianas. Dessa forma, sob os fundamentos da Psicologia Histórico-Cultural, conclui-se que, na escola, a aprendizagem produz a transformação dos conceitos espontâneos em científicos e, principalmente, o desenvolvimento dos próprios conceitos científicos, "pois ela [a escola] é o momento decisivo e determinante de todo destino do desenvolvimento intelectual da criança" (Facci, 2004a, p. 225). A esse respeito, Duarte (2008) comenta que a passagem ao pensamento por conceitos é um divisor de águas no desenvolvimento psíquico do indivíduo, engendrando o desenvolvimento da personalidade, em que a concepção de mundo do sujeito passa a ser guiada por esse "novo" modo de pensamento. De acordo com Duarte, Nessa concepção vigotskiana do desenvolvimento da
personalidade por meio do conhecimento mais profundo da
realidade objetiva (incluídas nesta as ações realizadas pelos
seres humanos e pelo próprio indivíduo em desenvolvimento)
evidencia-se a importância da educação escolar, da
transmissão do saber objetivo pelo trabalho educativo na
escola. Ao conseguir que o indivíduo se aproprie desse saber,
convertendo-o em "órgão de sua individualidade", segundo
uma expressão de Marx, o trabalho educativo possibilitará
ao indivíduo ir além dos conceitos cotidianos, superá-los, os 
quais serão incorporados pelos conceitos científicos. Dessa forma, o indivíduo poderá conhecer de forma mais concreta, pela mediação das abstrações, a realidade da qual ele é parte (Duarte, 2008, p. 82).

Com base em Vigotskii (1988), pode-se adensar a questão do desenvolvimento psíquico por meio do conhecimento da realidade objetiva. Em especial, a partir do constructo teórico acerca das relações entre o nível de desenvolvimento real (ou atual) e da zona de desenvolvimento iminente (ou próximo) ${ }^{2}$, as quais explicam a relação entre aprendizagem e desenvolvimento. O nível de desenvolvimento real é constituído, principalmente, por aquilo que já foi apropriado pelo sujeito, ou seja, por aquilo que o sujeito consegue realizar sem auxílio de outrem. Já a zona de desenvolvimento iminente é identificada pelas tarefas, operações, ações e atividades, cujo manejo e solução só se tornam viáveis por meio de imitação da criança e do auxílio de adultos ou outras pessoas mais experientes. De acordo com Facci (2004a, p. 225), no contexto escolar é fundamental "a criança aprender o novo, por isso, é a zona de desenvolvimento próximo que determina o campo das mudanças acessíveis à criança, é ela que representa o momento mais importante na relação da aprendizagem com o desenvolvimento".

Assim, a aprendizagem produz uma zona de desenvolvimento iminente, possibilitando a internalização pelo sujeito da cultura humana historicamente produzida a partir das relações sociais - dimensão interpsicológica. Ao serem ensinados e apropriados, os conceitos científicos passam a compor a individualidade - dimensão intrapsicológica - podendo tornar os elementos da cultura recheados de sentido para o sujeito, criando um novo nível de desenvolvimento real, que por si só cria diversas outras zonas de desenvolvimento iminentes possíveis, num movimento incessante de complexificação psíquica. Sendo assim, afirma-se que a aprendizagem escolar orienta e potencializa os processos de desenvolvimento, de modo que a aprendizagem possa produzir a gênese das zonas de desenvolvimento iminentes:

2 Segundo Prestes (2012), a correta tradução do conceito zona blijaichego razvitia do russo para português seria zona de desenvolvimento iminente, ao invés de zona de desenvolvimento proximal, utilizado nas primeiras traduções norte-americanas; ou zona de desenvolvimento imediato, opção feita pelo tradutor Paulo Bezerra do livro intitulado "A construção do pensamento e linguagem", de Vigotski. De acordo com a autora (2012), nestas traduções há uma interpretação errada para o que Vigotski compreende desse conceito, posto que não transmite aquilo que é mais importante para o entendimento do mesmo: a "relação existente entre desenvolvimento e instrução e à ação colaborativa de outra pessoa" (p. 190). Defende que a tradução que mais se aproxima do termo em russo é zona de desenvolvimento iminente, "pois sua característica essencial é a das possibilidades de desenvolvimento, mais do que imediatismo e da obrigatoriedade de ocorrência, pois se a criança não tiver a possibilidade de contar com a colaboração de outra pessoa em determinados períodos da sua vida, poderá não amadurecer certas funções intelectuais e, mesmo tendo essa pessoa, isso não garante, por si só, o seu amadurecimento" ( $p$. 204-205). Desta forma, no presente artigo utilizaremos o termo zona de desenvolvimento iminente, com exceção das citações e referências em que será mantido o termo utilizado no original (zona de desenvolvimento proximal).
“... o processo de desenvolvimento segue o da aprendizagem, que cria a área de desenvolvimento potencial [iminente]" (Vigotskii, 1988, p. 116). Segundo o autor, há uma dependência complexa, recíproca e dinâmica que rege a unidade aprendizagem-desenvolvimento, de modo que um não possa existir sem o outro.

Com isso, percebe-se que a aprendizagem escolar acaba por movimentar as funções psicológicas que se encontram em vias de desenvolvimento. É nesse contexto que Vigotskii (1988) retoma o fato de a aprendizagem preceder o desenvolvimento, atribuindo às condições de ensino criadas na escola a função de promover para o desenvolvimento das funções psicológicas superiores, de modo a direcionar o aluno à apropriação do conhecimento científico e de movimentar o próprio processo do conhecimento.

Sob tais fundamentos Facci (2004a) afirma que cabe ao professor, no processo educativo, possibilitar o processo de apropriação do gênero humano, ou seja, das objetivações humanas produzidas e acumuladas ao longo da história, por parte dos estudantes. Nesse mesmo sentido, a autora esclarece que

Partimos do pressuposto de que a escola tem como função... socializar os conteúdos já elaborados pela humanidade, de forma que os alunos possam participar do processo de humanização, isto é, levar o aluno a se apropriar dos elementos que os indivíduos da espécie humana necessitam assimilar para se tornarem humanos. Para tanto, a educação tem que partir, sempre, do saber objetivo, produzido historicamente, transformando-o em conteúdos curriculares. (Facci, 2007, p. 146).

Contudo, em razão do predomínio histórico no campo da educação escolar de teorias filosóficas, psicológicas e pedagógicas não críticas $^{3}$, resultado do projeto político-econômico da sociedade capitalista, intensificam-se as limitações a essa forma de apropriação do conhecimento e, consequentemente, ao desenvolvimento psíquico dos estudantes. Especialmente, por conta de tendências pedagógicas hegemônicas que, afinadas às demandas do capital, produzem a secundarização do papel do professor, a ne-

3 Meira (2012), ao tratar do problema do pensamento crítico na Psicologia e ao definir o conceito de crítica a partir do Materialismo Histórico-Dialético, define por contraposição o que é não crítico. Nesse caso, uma teoria não crítica. Para a autora, trata-se de teorias que, de modo dualista e mecanicista, ora enfatizam os aspectos subjetivos do individuo, concebendo o fenômeno psicológico como sendo internamente determinado, ora os aspectos objetivos, compreendendo o individuo como um ser determinado por fatores externos. E que tem como implicações: "a descontextualização e fragmentação do indivíduo, a psicologização do social e a naturalização dos fenômenos humanos como resultado da negação seu caráter fundamentalmente histórico, a desconsideração pelas desigualdades sociais e, concomitantemente, uma acentuada preocupação com a construção de teorias e técnicas dirigidas principalmente à adaptação social dos indivíduos" (p. 15). O pensamento crítico, ao contrario, é aquele que tem como elementos essenciais: "reflexão dialética; crítica do conhecimento; denúncia da degradação, da alienação e da heteronomia humana nas condições postas pelo capitalismo e a possibilidade de ser utilizado como um instrumento no processo de transformação social" (p.16). 
gação do ensino como transmissão do saber sistematizado produzido e acumulado pela humanidade, a desqualificação e o empobrecimento dos conteúdos científico-filosóficos. Como é o caso, atualmente, das Pedagogias do Aprender a Aprender, como as define Duarte (2004, 2008), as quais reduzem a escola e o professor a meros coadjuvantes do processo de aprendizagem do estudante, bem como restringem o conhecimento àquilo que lhe é útil e funcional na medida em que atenda suas necessidades pragmáticas, produzidas em seu cotidiano imediato alienado e alienante. Como é vida cotidiana de todo e qualquer indivíduo inserido em uma sociedade que se pauta em relações de dominação (Duarte, 2001, 2004). É deste processo de esvaziamento da escola e do papel do professor que se tratará a seguir.

\section{Pedagogias do Aprender a Aprender como expressão ideológica da materialidade da sociedade de classes contemporânea: negação do ensino de conceitos científicos}

Em razão da ampla difusão das Pedagogias do Aprender a Aprender no campo da educação escolar (Duarte, 2008), assiste-se, hoje, a uma hipertrofia de concepções individualizantes, espontaneistas, pragmáticas, imediatistas e não diretivas na escola, contrárias à transmissão do conhecimento sistemático historicamente produzido. Concepções essas que afastam a escola de seu papel no desenvolvimento das funções psicológicas superiores. Silva e Eidt (2010, p. 114) explicam que o "termo 'pedagogias do aprender a aprender' foi cunhado por Duarte e pode ser definido como um termo "guarda-chuva" que reúne os traços essenciais de diferentes correntes pedagógicas, entre elas, a Escola Nova, o Construtivismo, a Pedagogia das Competências e os estudos na linha do Professor Reflexivo".

Essas teorias enaltecem a concepção de que o estudante aprende por si mesmo, ou seja, de que ele constrói seu próprio conhecimento antes mesmo de ter se apropriado dos fundamentos teóricos para tal; de que "aprender a aprender", isto é, desenvolver um método de aprendizagem que possibilite ao sujeito aprender sozinho, deva ser a meta fundamental dos processos educativos; de que os conhecimentos disponibilizados na escola não devem se diferenciar dos conhecimentos adquiridos fora dela, ou seja, de que a escola deve se ater às necessidades e ao conhecimento prévio do estudante, em especial, àquilo que lhe é útil em termos de suas necessidades pragmáticas imediatas. Em suma, enaltecem a ideia de que é o estudante quem deve desenvolver um método de aquisição, elaboração, descoberta e construção do seu próprio conhecimento; um conhecimento prático que lhe se seja útil, a fim de que possa se adaptar fácil e rapidamente às transformações de sua realidade imediata, ou seja, que atenda prontamente as demandas que lhe são postas pela sociedade vigente 4 (Duarte, 2008).

4 Meira (2003) explica que os ideários do Aprender a Aprender, ao enfatizarem o conhecimento prático em detrimento do conhecimento teórico, dão margem ainda ao surgimento de concepções
Assim, a escola passa a formar indivíduos aptos a aprender qualquer tipo de conteúdo, contanto que lhe sirva de instrumento para adentrar no mercado de trabalho, isto é, para atender as necessidades dos postos de trabalho do capitalismo contemporâneo. Segundo Duarte (2004), na mesma medida em que na sociedade capitalista o trabalhador só é útil pelo seu valor de troca, pela sua força de trabalho, também na escola a aprendizagem somente é útil se gerar valores de troca, em que o conteúdo aprendido, seu valor de uso, não é tão útil assim. Útil é, sob tal lógica, o desenvolvimento da capacidade do indivíduo de aprender por si mesmo qualquer conteúdo, mesmo que superficialmente. $\mathrm{O}$ que o torna um indivíduo-trabalhador flexível, entendendo-se por isto um sujeito facilmente adaptável às oscilações da produção capitalista. Aqueles que não se flexibilizem em face destas condições serão considerados fracassados, desqualificados ou pouco empregáveis. Assim,

Quanto mais a difusão do conhecimento for regida pelas leis de mercado, mais superficial e imediatista vai-se tornando o conhecimento oferecido aos indivíduos e mais superficiais e imediatistas vão-se tornando as necessidades intelectuais desses indivíduos. Temos assim um círculo vicioso no qual o objetivo do lucro imediato vai gerando produtos mais ampla e facilmente consumíveis e, por sua vez, as necessidades e as preferências dos indivíduos vão-se empobrecendo cada vez mais (Duarte, 2004, p. 147).

Além disso, na medida em que essas pedagogias defendem a restrição das aprendizagens escolares ao que definem como aprendizagens significativas, que tenham sentido para o aluno, que tenham aplicação em seu cotidiano imediato extraescolar, reforçam a ideia de que os processos de ensino-aprendizagem se limitem às necessidades espontâneas dos alunos, concentrando-se, então, na aquisição de conceitos espontâneos e no desenvolvimento de um método de aprendizagem. Ao invés de focar o ensino de conhecimentos sistematizados já elaborados, “... acabam por negar a apropriação de conteúdos já elaborados, abandonando o acervo cientifico e privilegiando discussões não raro limitadas ao senso comum" (Klein, 2007, p.13). É nesse sentido que incentivam a construção autônoma do conhecimento, o que faz com que o papel do educador se limite a um promotor de estímulos para o desenvolvimento espontâneo do aluno, retirando-lhe a importância como participante do processo de reprodução e produção do conhecimento, relegando-o a posição de mero facilitador ou colaborador, uma vez que cabe ao estudante produzir sozinho seu próprio conhecimento (Facci, 2007) ${ }^{5}$.

É importante ressaltar que a lógica que sustenta a difusão destas correntes pedagógicas na atualidade não ocorre ao acaso, mas, como aponta Rossler (2004), resulta

mistificadoras acerca do papel do professor, como é o caso da teoria do professor reflexivo.

5 Ao contrário dessas concepções, a teoria vigotskiana, como já destacado, aponta como meta final do processo de escolarização a autonomia intelectual e o autodomínio da conduta do estudante. 
de modismo educacional que seduz parcela significativa de educadores, os quais a elas aderem sem reflexão crítica, acreditando serem a solução para os problemas educacionais existentes. $\mathrm{O}$ autor alerta que tal adesão

[...] só vem a contribuir para o agravamento do nosso quadro educacional e social atual, na medida em que essa postura muitas vezes reproduz e difunde no campo da educação ideias e práticas comprometidas com interesses ideológicos que contribuem com o esvaziamento da nossa educação e de seu objetivo essencial: a formação universal do indivíduo singular (Rossler, 2004, p. 2).

Assim, as Pedagogias do Aprender a Aprender contribuem para o esvaziamento do papel da escola e do professor no desenvolvimento psíquico dos seus estudantes, empobrecendo significativamente os processos de transformação dos conceitos espontâneos em conceitos científicos. Consequentemente, cerceando o desenvolvimento intelectual dos estudantes e, portanto, suas reais possibilidades de liberdade e autonomia, que se assentam na capacidade dos sujeitos de conhecerem a realidade e se autoconhecerem ${ }^{6}$. Ao se retirar a necessidade fundamental de se ensinar/ aprender os conhecimentos teórico-científicos na escola, amplia-se a distância entre o estudante e o gênero humano, acentuando-se processos de alienação a que estão submetidos os indivíduos na sociedade capitalista. Não só os afastando das conquistas da humanidade, como Ihes retirando as possibilidades concretas para pensar e transformar objetivamente essa sua realidade. Pensar pressupõe, necessariamente, o pensar por determinados conceitos - os científicos -, cuja explicação tem seus alicerces, seus fundamentos (Klein, 2007). Somente o pensamento teórico, cuja base são os conceitos científicos, pode tornar o "aluno alguém capaz de criar novas práticas e novas teorizações sobre o real" (Klein, 2007, p. 13).

As ideias falaciosas fortemente difundidas pelos ideários do Aprender a Aprender adensam, por sua vez, uma concepção individualizante acerca do desenvolvimento dos seres humanos.

A concepção individualizante, porém, não se faz presente apenas quando as análises centram-se na abstração de indivíduos isolados, mas quando, mesmo analisando-se o coletivo as relações interpessoais, as relações entre indivíduo e sociedade são interpretadas como resultado das necessidades individuais, tomadas como ponto de partida.

A concepção individualizante é difundida de muitas formas, entre elas pela difusão da ideologia do sucesso individual, que preconiza ser esse sucesso resultante da existência, no indivíduo, de algumas qualidades (quase poderíamos

6 A despeito de essas pedagogias apregoarem enfaticamente em seu discurso a autonomia e a liberdade dos sujeitos como meta da educação, consideramos que, contraditoriamente, elas produzem um efeito contrário. Caberia aqui discutir o que essas pedagogias consideram como autonomia e liberdade, no entanto, dado os limites deste artigo, deixaremos essa importante questão para outro momento. dizer "virtudes") como espírito empreendedor, criatividade, otimismo, perseverança, autoconfiança, disposição para o trabalho, domínio de técnicas atuais (tanto aquelas relativas à produção propriamente dita como aquelas relativas ao gerenciamento do empreendimento) e, principalmente, crença no princípio de que a sociedade só pode progredir se forem respeitadas as leis do mercado. (Duarte, 2004, p. 140).

Dessa forma, o individualismo exacerbado da sociedade contemporânea, expresso de um ponto de vista filosófico, psicológico e pedagógico pelas tendências educacionais contemporâneas, reforça a alienação do ser humano em todas as suas dimensões. Ou seja, como sintetiza Mészáros (2006, p. 19-20), baseado principalmente na obra Manuscritos Econômico-Filosóficos (Marx, 2004): a alienação da natureza, a alienação de si mesmo e de sua própria atividade, a alienação de seu ser genérico, a alienação em relação aos outros homens.

$\mathrm{E}$, de modo a justificar suas falácias, bem como o fato de que muitos dos indivíduos pertencentes à classe trabalhadora não estão conseguindo efetivamente "obter sucesso" em sua vida escolar e laborativa, essa mesma sociedade produz a ideologia necessária para legitimar as desigualdades entre os seres humanos - desigualdades, diga-se de passagem, que derivam da sociedade de classes antagônicas - deturpando o conceito de diferenças individuais. Conceito este muito caro às Pedagogias do Aprender a Aprender, na medida em que um dos seus principais lemas é a necessidade de se respeitar as especificidades de cada indivíduo, as quais são naturalizadas, isto é, tomadas por si mesmas, destituídas de sua constituição histórica e social.

Contrapondo-se a esta análise, Klein (2007) explica que há dois tipos qualitativamente distintos de diferenças individuais que podem ser observados no processo pedagógico: primeiro, as diferenças que não causam limitações significativas ou expropriantes para o sujeito, não influindo relevantemente em seu processo de desenvolvimento. Por exemplo, o aluno pode gostar mais de uma determinada cor do que de outra; de um dado tipo de brincadeira e não de outra, etc. Segundo, existem diferenças individuais que são social e ideologicamente construídas, resultantes das desigualdades sociais, e impeditivas da plena realização e do pleno desenvolvimento do sujeito. De acordo com Klein (2007), nesse caso, deve-se combater a essência dessas diferenças:

[...] o respeito aos indivíduos, em suas diferenças, significa não impor-Ihes atividades que não podem, efetivamente realizar, mas também e sobretudo, significa produzir meios e recursos que thes possibilitem realizar todas as atividades e necessidades que plenificam o ser humano.

Há, entretanto, diferenças que devem ser vigorosamente combatidas: são aquelas resultantes das desigualdades sociais, o que equivale a dizer que se deve combater essas desigualdades. Propostas aparentemente progressistas têm cometido o grave equívoco de acobertar a origem dessas 
diferenças, sob o pretexto de se estar "respeitando" as diferenças individuais. $\mathrm{Na}$ escola, isto tem sido feito sob a forma de mudanças curriculares que oferecem um conteúdo pobre aos filhos dos pobres, sob o argumento de que eles apresentam "dificuldades de aprendizagem" e, portanto, a escola deve adequar-se a essas dificuldades. Veja-se que, nesse caso, "adequar-se" significa acomodar-se a elas, oferecendo um ensino muito mais ralo e superficial aos filhos da classe trabalhadora. O que defendemos é exatamente o contrário: não se trata de ignorar essas dificuldades, mas de eliminar suas causas, de enfrentá-las, de não se acomodar a elas (Klein, 2007, p.5).

Vale ressaltar que a Psicologia, como ciência burguesa nascida no auge da consolidação histórica do capitalismo como modo de produção dominante, tem contribuído ideologicamente nesse processo, corroborando para o discurso das diferenças individuais como legitimação das desigualdades sociais. De acordo com Facci o Aprender a Aprender encontrou “... na psicologia, além dos fundamentos teóricos que lhe dão sustentação, uma forte aliada através dos testes psicológicos, dos conceitos de inteligência, que se propunham a explicar 'cientificamente' as diferenças individuais e, consequentemente, as desigualdades sociais" (Facci, 2004b, p. 104).

Depreende-se, do acima exposto, que ao desconsiderar as relações materiais existentes no processo de ensino-aprendizagem, abre-se caminho para concepção de matiz naturalizante relativa à condição humana, a qual se expressa, por exemplo, pela incapacidade ou pela falta de vontade e interesse em aprender conteúdos científicos. Sob os fundamentos da Psicologia Histórico-Cultural, patenteia-se que a não aprendizagem de tais conteúdos não é algo que se possa explicar apenas olhando-se para o indivíduo, posto que este fenômeno se funda nos limites que a sociedade de classes antagônicas impõe à formação humana, limites estes em sintonia, neste caso, com os princípios norteadores das Pedagogias do Aprender a Aprender.

Entender essa forma de teorização sobre o processo de construção do conhecimento implica reconhecer sob quais interesses e necessidades são valoradas práticas pedagógicas esvaziadas de conteúdo, com propostas curriculares que fragmentam conteúdos e se adéquam à realidade do estudante (Klein, 2007). A resposta, para Rossler (2004), é que estas propostas atendem aos interesses da materialidade do capitalismo hoje e reproduzem "os principais valores da sociedade contemporânea, isto é, reproduzem determinados elementos ideológicos fortemente presentes no cotidiano alienado de nossa sociedade" (Rossler, p. 5).

Impõe-se, dessa maneira, entender que essas propostas pedagógicas inviabilizam uma formação que articule os mais desenvolvidos conteúdos teórico-práticos produzidos pela humanidade, que tornem os indivíduos capazes de pensar e agir, entendendo a essência dos problemas que hoje afetam a vida social humana. O que requer, por sua vez, maiores níveis de abstração e elaboração, dependentes da apropriação dos e do pensar a partir dos conceitos científicos.

\section{Considerações Finais}

O intuito deste artigo foi problematizar o papel da escola na apropriação de conceitos científicos e, portanto, no desenvolvimento psíquico dos indivíduos em nossa sociedade. Além disso, como esse papel pode se alienar em razão do predomínio hoje de tendências pedagógicas afinadas com o ideário do aprender do a aprender. Em especial, por meio da secundarização da atuação intencional e sistematizada do professor nos processos de transmissão do conhecimento cientifico humano acumulado historicamente, em prol do espontaneísmo nas relações de ensino-aprendizagem e da hipertrofia do que é cotidiano e imediato na vida do aluno, possibilitando a eles apenas mediações fragmentadas e limitadoras que inviabilizam a apropriação dos fundamentos explicativos dos objetos do conhecimento (Klein, 2007).

Enfrentar tal desafio pressupõe o desenvolvimento do pensamento crítico no contexto escolar, o qual se pauta no processo de ir à raiz dos problemas sociais e dos conhecimentos que se pretenda ensinar/aprender. Concordando com Meira (2003), defende-se que a apropriação da reflexão crítica se coloca como necessidade fundamental à sociedade, porque se vive hoje num mundo em que tudo, inclusive o direito à educação, está entregue ao espírito mercantilista do capital. Numa perspectiva crítica, a escola deve fazer referência ao conhecimento sistemático desenvolvido e acumulado objetivamente ao longo da história humana e não ao conhecimento espontâneo; ao conhecimento fruto da prática e da teorização histórico-social humana e não ao conhecimento pragmático e construído individualmente; ao saber totalizante e não ao saber fragmentado; à cultura erudita e não ao senso comum fetichizado.

Assim, o que se propõe aqui é que o trabalho educativo seja "o ato de produzir, direta e intencionalmente, em cada indivíduo singular, a humanidade que é produzida histórica e coletivamente pelo conjunto dos homens" (Saviani, 2003, p. 13). O que implica, segundo o mesmo autor, que a Educação se volte para a identificação dos elementos culturais que precisam ser apropriados pelos estudantes - trata-se de distinguir entre o essencial e o acessório - e para a descoberta das formas mais adequadas para atingir esse objetivo, isto é, a organização dos meios - conteúdos, espaço, tempo e procedimentos - através dos quais, progressivamente, cada indivíduo singular realize, na forma de segunda natureza, a humanidade produzida historicamente.

Deste modo, defende-se o potencial humanizador que o contexto escolar pode oferecer aos indivíduos, na medida em que, de fato, a escola cumpra o papel de transmitir e socializar o conhecimento humano histórica e socialmente construído pela humanidade, de modo que esses conteúdos possibilitem aos estudantes o desenvolvimento do pensamento crítico, da consciência de si e do mundo. Por fim, pode-se dizer que esse é o tipo de Educação que efetivamente está comprometida em ser instrumento voltado à emancipação humana e à transformação das relações sociais alienantes e alienadas inerentes ao modo de produção capitalista. 


\section{Referências}

Abrantes, A. A. \& Martins, L. M. (2006). Relações entre conteúdos de ensino e processos de pensamento. Educação e Marxismo, n.1. Recuperado: 10 jan. 2016. Disponível: http://www2.fc.unesp. br/revista_educacao/arquivos/Relacao_entre_conteudos_de _ ensino_e_processos_de_pensamento.pdf.

Duarte, N. (2001). Educação Escolar, teoria do cotidiano e a escola de Vigotski ( $3^{\mathrm{a}}$ ed.). Campinas: Autores Associados.

Duarte, N. (2004). Vigotski e o "aprender a aprender": crítica às apropriações neoliberais e pós-modernas da teoria vigotskiana. Campinas: Autores Associados.

Duarte, N. (2005). O significado e o sentido. Revista viver mente \& cérebro, n. 2 - Lev Semenovich Vygotski: uma educação dialética. São Paulo: Coleção Memória da Pedagogia. São Paulo.

Duarte, N. (2008). Sociedade do conhecimento ou sociedade das ilusões?: quatro ensaios crítico-dialético em filosofia da educação. Campinas: Autores Associados.

Facci, M. G. D. (2004a). Valorização ou esvaziamento do trabalho do professor?: um estudo crítico-comparativo da teoria do professor reflexivo, do construtivismo e da psicologia vigotskiana. Campinas: Autores Associados.

Facci, M. G. D. (2004b). Teorias educacionais e teorias psicológicas: em busca de uma psicologia marxista da educação. Em N. Duarte (Org.), Crítica ao fetichismo da individualidade. Campinas: Autores Associados.

Facci, M. G. D. (2007). "Professora, é verdade que ler e escrever é uma coisa fácil?" - Reflexões em torno do processo ensinoaprendizagem na perspectiva vigotskiana. Em M. E. Meira \& M. G. D. Facci (Orgs.), Psicologia História-Cultural: Contribuições para o encontro entre a subjetividade e a educação. São Paulo: Casa do Psicólogo.

Klein, L. R. (2007). Fundamentos para uma Proposta Pedagógica para o Município de Campo Largo. Campo Largo, PR: PM/SED.

Leontiev, A. N. (1978). Atividad, consciência y personalidad. Buenos Aires: Ciencias del Hombre.

Luria, A. R. (1979). Curso de Psicologia Geral (vol. IV.). Rio de Janeiro: Civilização Brasileira.

Luria, A. R (1991). A atividade consciente do homem e suas raízes histórico-sociais. Em Curso de Psicologia Geral (vol. I). Rio de Janeiro: Civilização Brasileira.
Martins, L. M. (2011). O desenvolvimento do psiquismo e a educação escolar: contribuições à luz da psicologia histórico cultural e da pedagogia histórico-crítica. Tese de Livre Docência. Departamento de Psicologia da Faculdade de Ciências da Universidade Estadual Paulista, campus de Bauru, Bauru.

Marx, K. (2004). Manuscritos econômico-filosóficos. São Paulo: Boitempo.

Meira, M. E. M. (2003). Construindo uma concepção crítica de Psicologia Escolar: contribuições da Psicologia Histórico-Crítica e da Psicologia Sócio-Histórica. Em M. E. M. Meira \& M. A. M. Antunes (Orgs.), Psicologia Escolar: teorias críticas. São Paulo: Casa do Psicólogo.

Meira, M. E. M. (2012). A crítica da Psicologia e a tarefa da crítica na Psicologia. Psicologia Política, 12 (23). 13-26.

Mészáros, I. (2006). A teoria da alienação em Marx. São Paulo: Boitempo.

Rossler, J. H. (2004). A retórica construtivista: por que o construtivismo seduz? Em VI Encontro de Pesquisa em Educação da Região Sudeste: Política, Conhecimento e Cidadania, Rio de Janeiro.

Saviani, D. (2003). Sobre a natureza e a especificidade da educação. Em D. Saviani, Pedagogia histórico-crítica: primeiras aproximações. Campinas: Autores Associados.

Silva, G. L. R. \& Eidt, N. M. (2010). "Oposições teórico-metodológicas entre a psicologia histórico-cultural e o construtivismo piagetiano: implicações à educação escolar". Em Secretaria de Estado da Educação \& Superintendência da Educação (Orgs.), Organização do Trabalho Pedagógico (vol. 1, pp. 111-128). Curitiba: SEED.

Vigotskii, L. S. (1988). Aprendizagem e desenvolvimento intelectual na idade escolar. Em L. S. Vigotskii, A. R. Luria \& A. N. Leontiev (Orgs.), Linguagem, desenvolvimento e aprendizagem (5a ed.). São Paulo: Ícone, EDUSP.

Vygotsky, L. S. (1997). Obras escogidas. Tomo I. Madrid: Visor.

Vygotsky, L. S. (1998). Pensamento e Linguagem (2ª ed.). São Paulo: Martins Fontes.

Prestes, Z (2012). Quando não é quase a mesma coisa: traduções de Lev Seminovitch Vigotski no Brasil. Campinas: Autores Associados. 


\section{Sobre os autores}

Patricia Verlingue Ramires Monteiro (pativrm@gmail.com)

Mestranda em Psicologia na linha de Educação, Trabalho e Produção de Subjetividade - Universidade Federal do Paraná (UFPR).

Graziela Lucchesi Rosa da Silva (grazielaluc@hotmail.com)

Docente no curso de graduação em Psicologia da Universidade Federal do Paraná (UFPR) e doutora em Educação pela mesma instituição.

João Henrique Rossler (joheross@yahoo.com.br)

Doutor em Educação Escolar pela Universidade Estadual Paulista Júlio de Mesquita Filho - UNESP. Docente do Mestrado em Psicologia da UFPR na linha de Educação, Trabalho e Produção de Subjetividade - Universidade Federal do Paraná (UFPR). 